\title{
A Computer-Based Tool for Introducing Turfgrass Species
}

\author{
T. W. Fermanian* and D. J. Wehner
}

\begin{abstract}
An essential component of an introductory turfgrass management course is the description of how turfgrass species are adapted to different cultural systems and environments. The objectives of this project were to develop an interactive program to introduce the characteristics of turfgrass species and their optimum environments and to evaluate the students' gain in understanding turf species characteristics through this approach. A self-contained application, Turf Species, was constructed using the SuperCard development tool. Turf Species consists of three sections including a self-paced tour of the species, a what if establishment section, and randomly composed reinforcement quizzes with automatic grading. Turf Species was designed to be distributed to students on diskette for self-paced study and reinforcement of material presented during previous lectures. Each student who used the Turf Species tool spent approximately $2 \mathrm{~h}$ evaluating the program. Seventy-one percent of the student evaluators felt that the graphic representations or illustrations for each species aided in their understanding of the material. All of the evaluators indicated that the testing module helped in their understanding of the turf species, and $\mathbf{8 6 \%}$ of them suggested that the Turf Species program should be used more extensively in the introductory turfgrass management course. An evaluation of the test scores found on returned diskettes showed an average examination grade of $52 \%$ with a range from 5 to $100 \%$.
\end{abstract}

\begin{abstract}
A PPROXIMATELY 10 to 25 students enroll in the introductory turfgrass management course at the University of Illinois at Urbana-Champaign each fall semester to explore the world of managing fine turfs. For many, this experience will be their only formal training in the area. A major objective of the course is to teach students how to select appropriate turfgrass species whose growth characteristics best match a particular cultural system. In this approach, the genetic potential of a plant is closely matched to the constraints of the intended environment. This is considered the most environmentally sound method of managing turfs. Turfgrasses that are closely adapted usually require minimal fertilization, irrigation, and a reduced need for using pesticides (Balogh et al., 1992).

More than 20 grass species are used for turfgrass across the USA (Turgeon, 1992). The introduction of these species and their attributes represents a difficult learning situation for new students. The absence of distinctive characteristics such as flower color or growth habit make grasses more difficult to remember than other plant material. Also, students are being exposed to many other species through concurrent enrollment in horticulture
\end{abstract}

Department of Hortic., Univ, of Illinois, 1102 S. Goodwin Ave., Urbana, IL 61801. Contribution from the Illinois Agric. Exp. Stn., Urbana. Received 25 Apr. 1994. *Corresponding author (fermo@ uiuc.edu).

Published in J. Nat. Resour. Life Sci. Educ. 24:45-48 (1995). plant material courses. Presently, turf species are introduced to students through static, paper-based data sheets. With this format, a single data sheet is presented for each species. Other media-such as $35-\mathrm{mm}$ slides and textbooks-are used to show pictorial representations of the important visual characters of each species. Students are also shown live specimens in the lab and field. They can view differences or similarities among the species due to the format consistency of the data sheets. Many of the major associations between plant characteristics and environmental requirements are presented during lecture. Although laboratory periods are designed to introduce grass morphology and to relate form to function, time does not permit students to explore all the possible combinations of turf species and enviornments. Additional independent study would be useful to explore case studies of attempts to match turf species to particular environments.

One possible opportunity for independent study is through the use of interactive software to allow students to generate what if scenarios of turf establishment. A selfguided browsing tool would allow students to independently expand on their classroom introduction to the turf species.

Our objectives in developing Turf Species were: (i) to develop an interactive program to introduce the plant characteristics of turf species and their optimum environments; and (ii) to develop a mechanism within the program for students to evaluate their understanding of turf species characteristics through this approach.

\section{PROGRAM DESCRIPTION}

Turf Species was developed using the SuperCard development system on a Macintosh Quadra 700 microcomputer. The development workstation had 20MB of RAM with a 16-inch $(40.6-\mathrm{cm}), 24$-bit color display. Turf Species can run in as little as $1600 \mathrm{~KB}$ of RAM. Since it was designed to use only black and white, it can be run on any Macintosh configuration. Many of the individual components of Turf Species are connected through hypertext links. Hypertext is a programming technique to provide a form free structure for displaying information. Key words within the body of the text are designated as links. These links take the user directly to text of related issues also with further links. Hypertext allows users to view related information without moving through a series of menus. Technical information on grass species was developed by the authors and supplemented by a variety of commonly available turf references (Shurtleff et al., 1987; Turgeon, 1992).

The main menu for Turf Species provides access to three components or sections (Fig. 1). The first component is a tour of the species grouped into four categories. Students can view the turf species by their best regional location of adaptation, their adaptation to different 


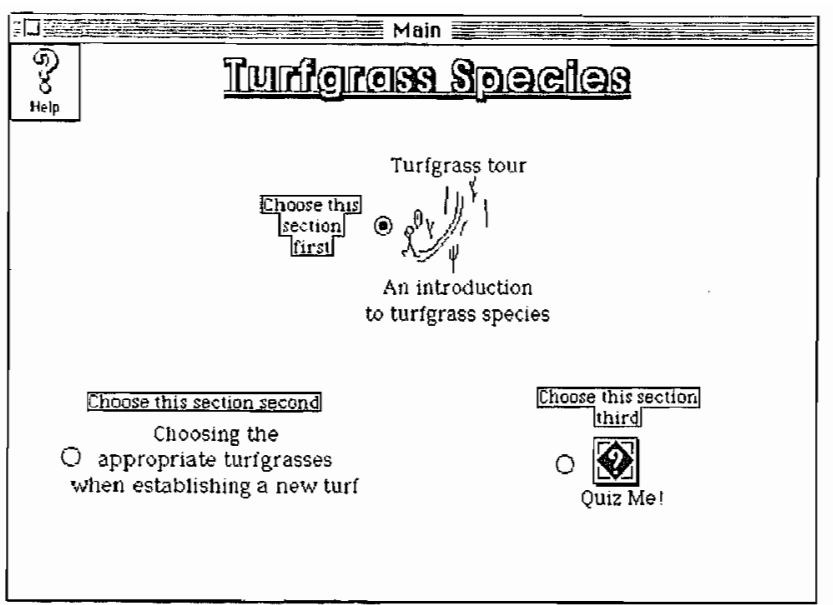

Fig. 1. Main menu of Turf Species.

management programs, their adaptation to local sitespecific micro-environments or view an alphabetical list by common or scientific name. The second component is a mechanism for developing species groupings that are best adapted to selected establishment criteria. The third component involves a series of randomly selected test questions for student self-testing. After each menu or new card within the project, a second text-based card appears, providing instructions or background information. All cards have a help button in the upper left corner (Fig. 1) for multilevel help on the function and use of the program.

\section{Turfgrass Tour}

In the initial tour section, students are presented with various choices for species grouping. Species are either grouped by regional site of adaptation, management programs, intended use of the turf, or simply by common or scientific name. Within the tour, a map button exists to move rapidly from one area to another (Fig. 2). The map button also provides a flow chart for the establishment section. Each of the buttons available on the initial card brings up a subsequent card with additional buttons to create the final species grouping. Generally, there are one or two cards for each possible path. When a selection is made, a second window displays a list of all the grass species that meet the selection criteria. The main window then displays these species in sequential order.

Each species is represented by two data sheet cards that have information including plant characteristics, identification characteristics, and general uses for the species. Additional buttons are available on each of the cards for displaying commonly available varieties, an illustration of the species, and movement to an additional card. On the second card, information about reproduction, adaptation, and any special problems is provided. Students may move randomly among the list of species displayed in the second window. As each card in the main window is viewed, the common and scientific names listed in the second window are underlined to provide feedback on the species already seen.

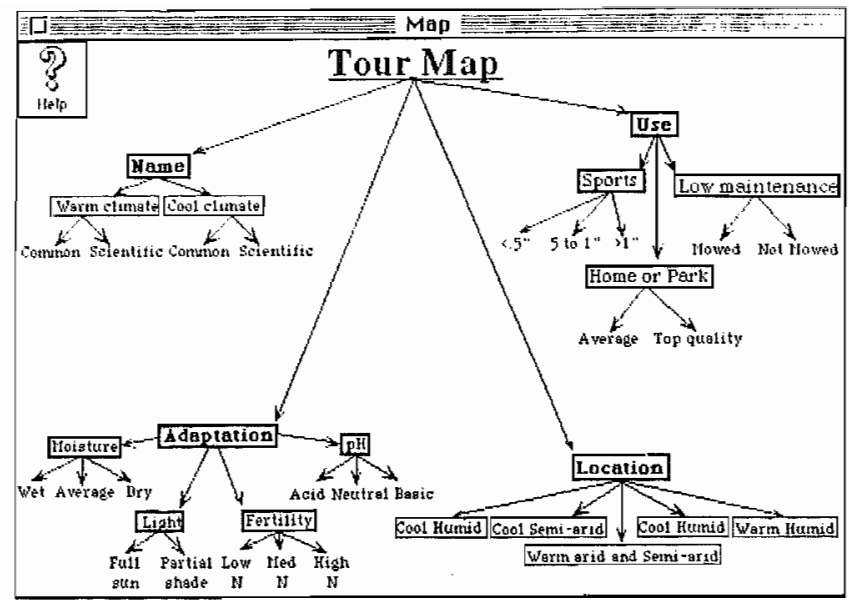

Fig. 2. Tour Map overview screen.

\section{Establishment Component}

Another selection available from the main menu is labeled "Choosing the appropriate turfgrasses when establishing a new turf' (Fig. 1). When this option is selected, a hierarchical map appears showing all of the categories that classify the grasses. This map is similar to the Tour Map shown in Fig. 2. Students are prompted to select all the criteria that match their proposed establishment. As each criterion is selected, a pop-up window provides a listing of the choices already made. The choices are strung together with AND or OR boolean connections. An OR connection can be made by holding down the option key when making the selection. After all criteria have been selected, a match-it button is pressed to find species that exactly match the boolean string. The selected species then appear in a window with the main species data card window. These two windows are exactly the same as those provided in the tour section and function in the same manner. The student can see all of the species that meet the requested criteria for establishment.

\section{Testing Component}

In a third section, students can take a short quiz on the information presented in the first two components. The total value of all the questions listed on a card is displayed in the upper right corner of that card. When all questions are answered the student can move to the next card by pressing the "Score page" or "Next quiz" buttons. If "Score page" is selected, the correct answers are displayed. With either choice, the number of correct points, along with the total possible points, is listed. New cards of questions are randomly selected until the total possible points for questions on all presented cards is greater than 100 or the "End quiz" button is selected. A total of 100 points was selected to represent a typical exam covering this subject matter presented in the course.

In the quiz section, a variety of question types are presented to the students. Most of the questions are truefalse or matching. One unique question type is graphic labeling (Fig. 3). A pop-up menu is presented for each graphic. As a student selects a label, it is removed from 


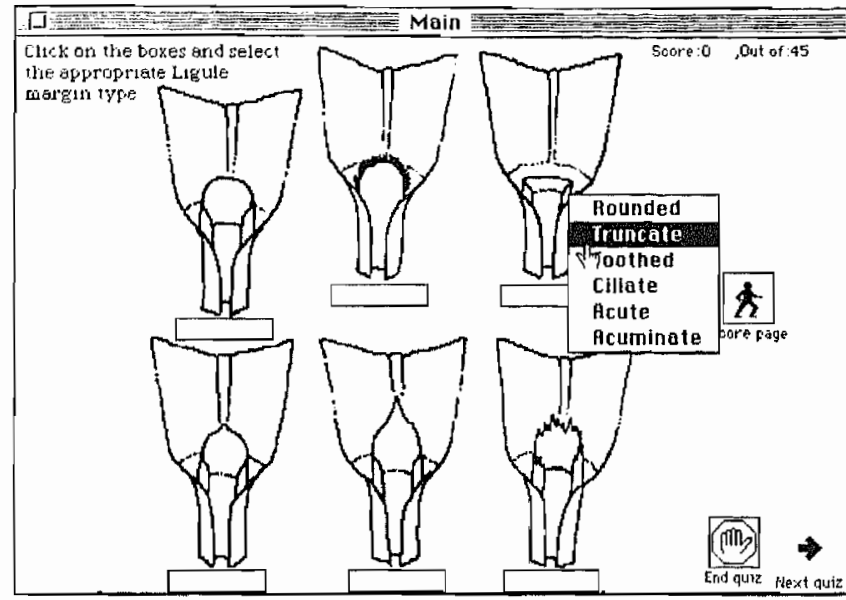

Fig. 3. Fill-in-the-blank quiz page in Quiz component.

the list for other pictures, but changes can be made at any time.

At the conclusion of a quiz, the answers to all the questions are provided. An indication of correct and wrong answers is shown. Students can click on any quiz answer and the original questions for that card will appear with an $\mathrm{X}$ marked by questions with wrong answers. A button is available to display the correct answers. After the students have explored the results of their quiz, they can go back to the initial quiz card and try another quiz or exit the quiz section. The answers to each quiz, quiz scores, and the student's name are written to an external ASCII file for data analysis by the instructor.

\section{EVALUATION}

Turf Species has been used by students in several introductory turfgrass management courses. Students in the fall 1993 course were asked to evaluate the usefulness of the program. Waddell and Rinke (1985) suggest this is an important step in the evaluation of any computeraided instruction software. Fifteen students were enrolled in the class with 13 students participating in the evaluation. Six of the 13 students responding to the survey did not use the Turf Species program. Of the six students, $84 \%$ listed "too busy" as a reason for not evaluating the program while $16 \%$ had trouble getting the program to work.

Each of the seven students who used Turf Species spent approximately $2 \mathrm{~h}$ evaluating the program. Seventy-one percent of the students who evaluated the program felt that the graphic representations or illustrations for each species helped their understanding of the material, whereas approximately $29 \%$ felt it was of little value (Table 1). Other studies support the use of visual techniques to present ideas or concepts (Stephens and Doherty, 1992). All of the participating students felt the testing module helped in their understanding and $86 \%$ of the students suggested the Turf Species program should be used more in the introductory turfgrass management course.

In a separate question, students were asked how they thought Turf Species helped them the most. Their
Table 1. Student perceptions of Turf Species.

\begin{tabular}{lccc}
\hline & Response \\
\cline { 2 - 4 } & Yuestion & No & No \\
\hline & 86 & 14 \\
& 86 & 14 \\
Did you find Turf Species essy to use? & 71 & 29 \\
$\begin{array}{l}\text { Did you find the program useful? } \\
\text { Did the graphics add to your understanding of the } \\
\text { material? }\end{array}$ & 100 & 0 \\
$\begin{array}{l}\text { Did the testing module assist you in your understanding } \\
\text { of the material? }\end{array}$ & 86 & 14 \\
\hline $\begin{array}{l}\text { Should the Turf Species program be used more in the } \\
\text { introductory course? }\end{array}$ & & \\
\hline
\end{tabular}

responses were split almost evenly between using it to review for a test $(57 \%)$ and to develop an initial understanding of the turf species $(43 \%)$.

The results of individual quizzes taken by the students within the stack are written to an ASCII file on each of the program diskettes. An evaluation of the test scores found on returned diskettes showed an average examination grade of $52 \%$. There was a wide range in test scores from a low of $5 \%$ to a high of $100 \%$.

\section{DISCUSSION}

We believe that Turf Species offers a significant tool in the interactive exploration of grasses used for turf purposes. Turf Species could be used more effectively if the species are introduced previously in class. This has been supported in other studies (Creasy, 1986). Students evaluating the project overwhelmingly supported its continued use in the introductory turfgrass management course. As with most software projects, Turf Species is not complete. Revisions of the illustrations and cultivar lists are continuing. Additional funding has been secured to add video sequences to the project.

\section{SOFTWARE SPECIFICATIONS}

Turf Species is available as either a SuperCard project or an independent application. The application will run on any Macintosh computer with MacOS 6.05 or greater and at least $1600 \mathrm{~KB}$ of free RAM. The screen size of windows in Turf Species has been set for a default of 342 $X 512$ pixels but can expand to any size on the current screen.

Turf Species has been copyrighted by the authors. it can be obtained on a 3.5-inch diskette for a $\$ 30$ distribution fee to help defray production and handling costs. Those with access to the Internet may obtain it through anonymous ftp from $\mathrm{kbml}$.hort.uiuc.edu in the "/pub/turf" folder.

\section{ACKNOWLEDGMENTS}

We thank the Apple Computer Co. and the Illinois Turfgrass Foundation for partial funding of this project. We also thank Dr. Gary J. Kling for his review of the manuscript.

\section{REFERENCES}

Balogh, J.C., A.R. Leslie, W.J, Walker, and M.P. Kenna. 1992. Development of integrated management systems for turfgrass. $p$. 
355-478. In J.C. Balogh and W.J. Walker (ed.) Golf course management and construction: environmental issues. Lewis Publ., Boca Raton, FL.

Creasy, L.L. 1986. Application of an apple production and profitability microcomputer model in pomology teaching. HortSci. $21: 1176-1177$.

Shurtleff, M.C., T.W. Fermanian, and R. Randell. 1987. Controlling turfgrass pests. Prentice-Hall, Englewood Cliffs, NJ.
Stephens, P.J., and J.A. Doherty. 1992. The use of Apple Macintosh computers and Hypercard in teaching physiology laboratories. Am. J. Phys. 263:S23-S28.

Turgeon, A.J. 1992. Turfgrass management, 3rd ed. Prentice-Hall, Englewood Cliffs, NJ.

Waddell, K.P., and W.J. Rinke. 1985. Effectiveness of a computerassisted instruction program for teaching sanitation. J. Am. Diet. Assoc. 85:62-67. 